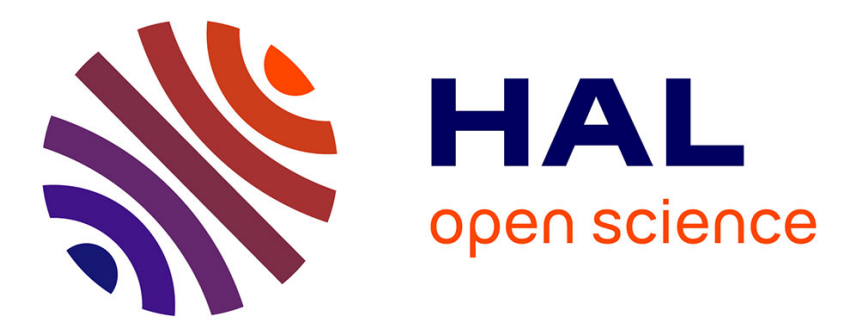

\title{
Identification and validation of a continuum damage model applied for the lifetime prediction of $\mathrm{H} 11$ tool steel
}

\author{
Vincent Velay, Gérard Bernhart, Denis Delagnes
}

\section{To cite this version:}

Vincent Velay, Gérard Bernhart, Denis Delagnes. Identification and validation of a continuum damage model applied for the lifetime prediction of H11 tool steel. International Journal of Microstructure and Materials Properties, 2008, 3 (2-3), p.282-296. 10.1504/IJMMP.2008.018735 . hal-01851422

\author{
HAL Id: hal-01851422 \\ https://hal.science/hal-01851422
}

Submitted on 6 Nov 2019

HAL is a multi-disciplinary open access archive for the deposit and dissemination of scientific research documents, whether they are published or not. The documents may come from teaching and research institutions in France or abroad, or from public or private research centers.
L'archive ouverte pluridisciplinaire HAL, est destinée au dépôt et à la diffusion de documents scientifiques de niveau recherche, publiés ou non, émanant des établissements d'enseignement et de recherche français ou étrangers, des laboratoires publics ou privés. 


\title{
Identification and validation of a continuum damage model applied for the lifetime prediction of H11 tool steel
}

\author{
V. Velay*, G. Bernhart and D. Delagnes \\ CROMeP (Research Centre On Tools Materials and Processes) \\ Ecole Mines Albi, France \\ E-mail: vincent.velay@enstimac.fr \\ E-mail: gerard.bernhart@enstimac.fr \\ E-mail: denis.delagnes@enstimac.fr \\ *Corresponding author
}

\begin{abstract}
This paper describes the work performed to identify and validate a non-isothermal continuum damage model for a widely used hot-work tool steel $\mathrm{H} 11$ at a hardness of $47 \mathrm{HRc}$. The investigation is based on an extensive high-temperature low-cycle fatigue database performed under strain rate controlled tests with and without dwell times in the range of $300^{\circ} \mathrm{C}-600^{\circ} \mathrm{C}$. The approach gives a good description of the thermomechanical behaviour of $\mathrm{H} 11$ tool steel under various test conditions and constitutes a very good prediction tool for a very large amount of fatigue tests. This work is divided into three stages. First, isothermal fatigue tests are performed on flat specimens in order to identify lifetime model parameters. Then, thermo mechanical fatigue tests are considered in order to validate the model in a non-isothermal case. Lastly, low-cycle fatigue tests are carried out on notched specimens in order to investigate the model capabilities in a multiaxial condition.
\end{abstract}

Keywords: continuum damage model; lifetime prediction; low-cycle fatigue test; thermo mechanical test; notched specimen.

Biographical notes: Vincent Velay received his MS in Applied Mathematics from the Paul Sabatier University in Toulouse and his PhD in Material Science from Ecole des Mines de Paris. The focus of his research is understanding and modelling the behaviour of metallic materials in order to assess their lifetimes. His research is interdisciplinary and brings together the fields of numerical mechanics and material science. Dr. Velay is an Associate Professor at the Ecole des Mines d'Albi-Carmaux in France and a Researcher in the Research Centre on Tools, Materials and Forming Processes.

Gérard Bernhart received his MS and $\mathrm{PhD}$ degrees in the field of Applied Mechanics. Currently, Gérard Bernhart is a Professor at the Ecole des Mines d'Albi-Carmaux. He is also the Director of the Research Centre on Tools Materials and Processes, Albi, France. His scientific topics include tool steel behaviour and damage. He has published a great number of scientific and technical papers in this research field. His current research interests focus on the composite processes. 
Denis Delagnes received his MS in Solid State Physics from the National Institute of Applied Science in Toulouse and his $\mathrm{PhD}$ degree from Ecole Nationale Supérieure des Mines de Paris. Currently, Dr. Delagnes is an Associate Professor at Ecole des Mines d'Albi-Carmaux (EMAC), and a Researcher in the Research Centre on Tools, Materials and Forming Processes $(\mathrm{CROMeP})$ in the Materials Structure, Behaviour and Durability team. His current scientific topics include tool steel behaviour and damage as well as establishing relations between the martensitic microstructure and the resulting mechanical properties.

\section{Introduction}

Hot-work tool steels undergo critical thermo mechanical loads, which are very hard to assess from an experimental point of view. Numerical simulation seems to be adequate to provide the strain-stress response induced in the tool. It allows to optimise the tool design and to improve its lifetime. However, several preliminary stages are necessary. First, a cyclic elasto viscoplastic behaviour model has to be identified from one dimensional fatigue tests, then it has to be implemented in a finite element software to predict strain and stress levels in the tools during the forming processes. Afterwards, all these parameters can be introduced in a lifetime model whose values are themselves identified from uniaxial fatigue tests. Lastly, both of these approaches (behaviour and damage models) have to be implemented in order to be tested in a multiaxial condition. This paper describes the complete lifetime methodology. The behaviour part of this investigation is briefly recalled. The model formulation is based on previous works (Velay et al., 2006; Cailletaud and Sai, 1995; Ahmer et al., 2006; Lemaître and Chaboche, 1994); it allows to describe cyclic softening, strain rate and dwell time effects and constitutes a very complete approach. Afterwards, a continuum damage model is identified. It considers the stress as a critical value to quantify a damage evolution. Several authors have developed lifetime models in such a framework (Chaboche and Lesne, 1998; Velay et al., 2005; Nicouleau-Bourles, 1999; Gallerneau, 1995; Shi et al., 2000; Xiao, 2004). The fatigue test necessary to identify the model are presented in the first section. Then, two validation stages are performed. The first one includes non-isothermal tests, whereas the second one considers fatigue tests performed on notched specimens.

\section{Material and testing}

AISI H11 tool steels under cyclic test conditions are characterised by a continuous cyclic softening from the first cycle up to rupture of the material. Indeed, a strong softening occurs during the first hundreds of cycles followed by a steady softening phase for the major part of the lifetime and lastly, crack initiation induces a strong decrease of the stress amplitude.

The chemical composition of AISI H11 tool steel is presented in Table 1 and heat treatment operations are illustrated in Table 2. It consists of austenitising, quenching and two tempering operations, which confer to the material a nominal Rockwell hardness of $47 \mathrm{HRc}$. 
Table 1 Chemical composition of AISI H11 tool steel

\begin{tabular}{lcccccccc}
\hline $\begin{array}{l}\text { Main allowing } \\
\text { elements }\end{array}$ & $\mathrm{C}$ & $\mathrm{Ni}$ & $\mathrm{Cr}$ & $\mathrm{Mo}$ & $\mathrm{V}$ & $\mathrm{Si}$ & $\mathrm{Mn}$ & $\mathrm{Fe}$ \\
\hline Weight $(\%)$ & 0.40 & 0.20 & 5.05 & 1.25 & 0.47 & 0.92 & 0.49 & bal \\
\hline
\end{tabular}

Table 2 Heat treatment operations of AISI H11 tool steel

\begin{tabular}{lcccc}
\hline Austenitising & Quenching & 1st tempering & 2nd tempering & Hardness \\
\hline $990^{\circ} \mathrm{C}$ & $1 \mathrm{~h} / \mathrm{gas}$ & $2 \mathrm{~h} / 550^{\circ} \mathrm{C}$ & $2 \mathrm{~h} / 605^{\circ} \mathrm{C}$ & $47 \mathrm{HRc}$ \\
\hline
\end{tabular}

Moreover, Table 3 describes the evolution of the material properties of the material with temperature.

Table 3 Material properties of AISI H11 tool steel

\begin{tabular}{lrrrrrr}
\hline Temperature $\left({ }^{\circ} \mathrm{C}\right)$ & 20 & 200 & 300 & 400 & 500 & 600 \\
Young modulus E (GPa) & 210 & 195 & 190 & 182 & 167 & 147 \\
True elactic limit $\mathrm{R}_{0}(\mathrm{MPa})$ & 710 & 680 & 610 & 560 & 520 & 500 \\
Conventional elastic limit $\mathrm{R}_{\mathrm{p} 02}(\mathrm{MPa})$ & 1230 & 1075 & 1015 & 870 & 740 & 420 \\
Ultimate stress $\mathrm{R}_{\mathrm{m}}(\mathrm{MPa})$ & 1460 & 1350 & 1290 & 1230 & 1060 & 815 \\
\hline
\end{tabular}

In order to identify a continuum damage model (see below), isothermal fatigue tests were conducted; various conditions in terms of strain amplitudes and rates, dwell times within cycles, temperature levels were considered in order to have a lifetime model as accurate as possible. All these loading conditions were selected in order to be close to those induced in the hot-forming processes. Figure 1 shows the typical softening of the material for a strain range of $1.2 \%$, different strain rates, a temperature of $520^{\circ} \mathrm{C}$ (a) and $600^{\circ} \mathrm{C}$ (b) and different kinds of loads: Compressive Relaxation Test (CRT), Tensile Relaxation Test (TRT) and Triangular Test (TT). More information about the cycle shapes is provided in Figure 2. Forty-six isothermal fatigue tests were performed: they included temperature levels from $300^{\circ} \mathrm{C}$ to $600^{\circ} \mathrm{C}$, strain amplitudes from $+/-0.34 \%$ to $+/-0.9 \%$, strain rates from $10^{-4} \mathrm{~s}^{-1}$ to $2.810^{-2} \mathrm{~s}^{-1}$ and different tensile dwell times equal to 20 or $80 \mathrm{~s}$.

The number of cycles to failure are included in the range of 544 cycles for the most severe test conditions and 31500 cycles for the test with a low-strain amplitude performed at the temperature of $300^{\circ} \mathrm{C}$. All the results were presented in detail in a previous paper (Velay et al., 2005). 
Figure 1 Typical cyclic softening of AISI H11 steel (a) $\mathrm{T}=520^{\circ} \mathrm{C}$; (b) $\mathrm{T}=600^{\circ} \mathrm{C}$

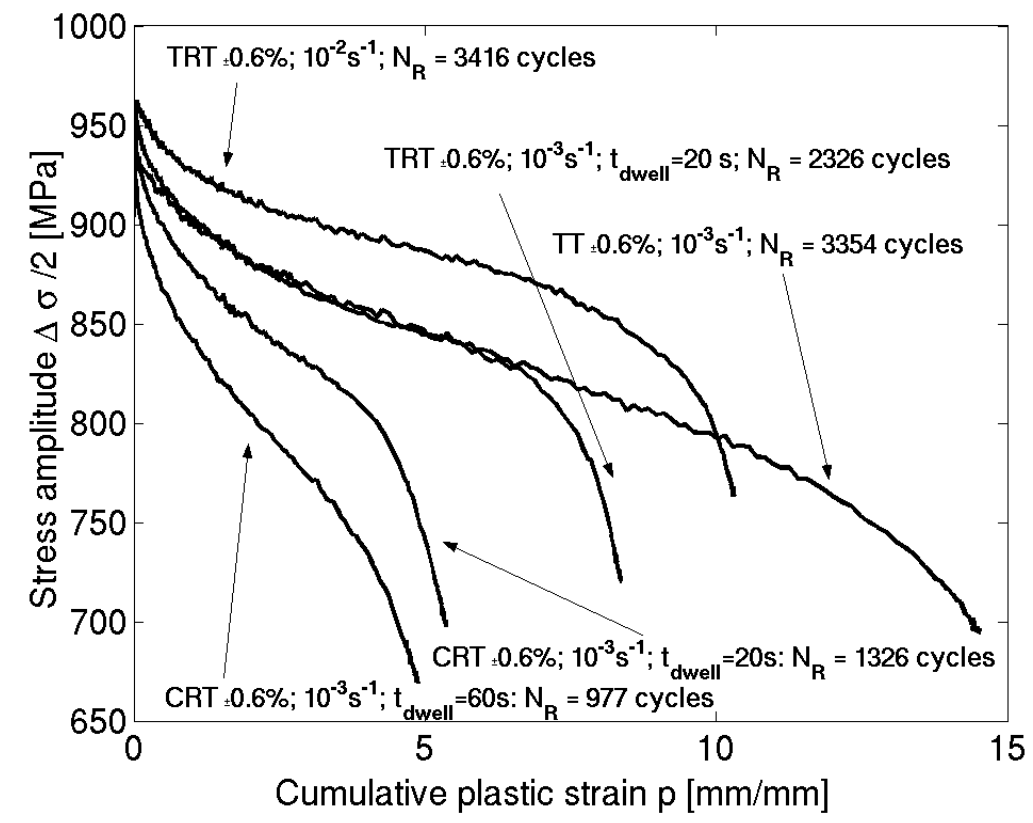

(a)

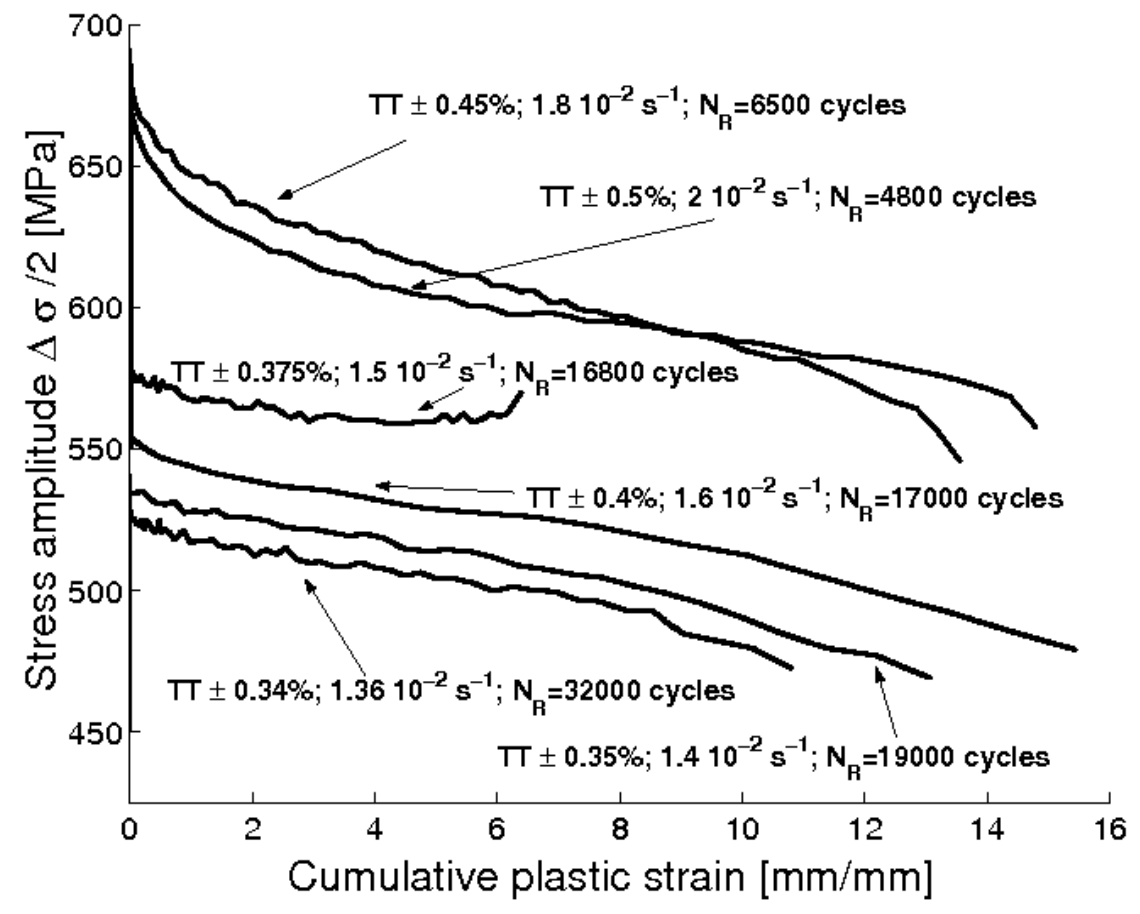

(b) 
Figure 2 Cycle shapes investigated: Triangular Tests (TT), Tensile Relaxation Tests (TRT) and

Compressive Relaxation Tests (CRT)

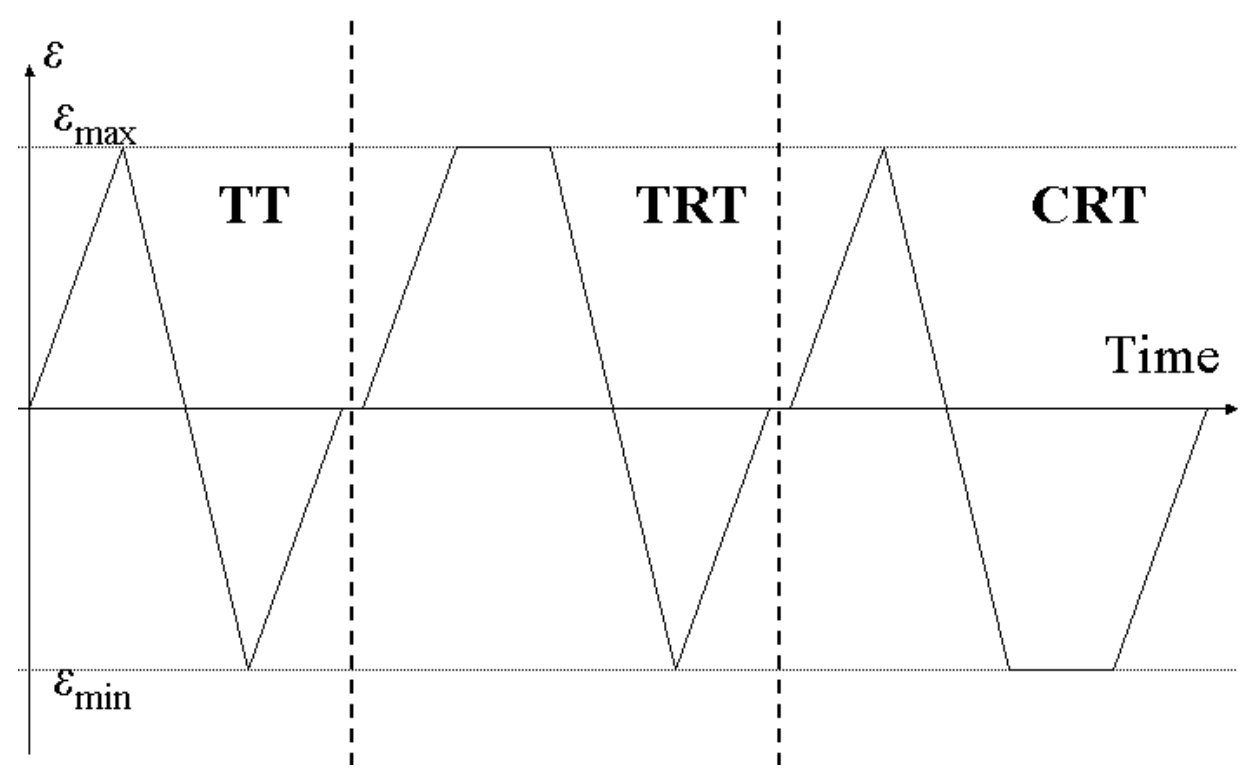

\section{Lifetime methodology}

Lifetime methodology is based on a continuum damage model (Velay et al., 2005; Nicouleau-Bourles, 1999; Gallerneau, 1995). It requires experimental isothermal strain-controlled fatigue tests conducted at different temperatures, several strain amplitudes and strain rates. Moreover, tensile dwell times can be included in the cycle as shown in the previous section. These tests allow the identification of the different model parameters depending on the material investigated and on the test temperature considered. The lifetime model also requires some additional parameters provided by the strain-stress response. Usually, this data can be provided by the experimental fatigue test itself and the stabilised cycle is selected. However, the H11 steel exhibits a continuous softening from the first cycle to the rupture of the material and the stabilised cycle cannot be clearly defined. A cycle at mid-life or occurring during the slow linear softening phase is then considered. However, in all the cases, the lifetime fatigue tests have to be performed in order to know the mid-life or stabilised cycle parameters.

\subsection{Cyclic behaviour modelling}

The methodology presented in this paper allows the determination of the mid-life parameters without performing all the tests. For that purpose, a behaviour model has to be identified and used as a complementary approach with the lifetime model. Identification methodology of the behaviour model parameters is quite complex and was presented in detail in a previous paper (Cailletaud and Sai, 1995). Several elasto-viscoplastic models were considered, all of them are in agreement with the irreversible processes of 
thermodynamic (Velay et al., 2006; Lemaître and Chaboche, 1994). They include a Von Mises Yield criterion to define the elasticity domain, a Norton law to consider the strain rate effect, a kinematic hardening to describe the fast evolutions of the material behaviour and an isotropic hardening to reproduce the slower evolutions (cyclic softening). Some additional phenomena were added in order to take into account dwell times within cycles (static recovery term) and stress-controlled tests. Figure 3 shows the results provided by the behaviour methodology. Figure 3(a) presents a comparison between experimental and calculated strain-stress response for a pseudo-stabilised cycle at a temperature of $600^{\circ} \mathrm{C}$; Figure 3(b) presents a comparison of the cyclic softening for different levels of test temperature. This methodology was validated by a comparison of the non-isothermal model response with out-of-phase compressive fatigue test (Oudin, 2002). These thermomechanical fatigue tests can also be used to validate the lifetime model (see validation result section). Moreover, behaviour models identified are able to reproduce all the fatigue lifetime tests performed and presented in the previous section (Velay et al., 2005). However, they cannot describe the fast decrease of the stress amplitude before the rupture of the material (crack initiation) and are not able to predict the lifetime. That is why they have to be combined with a lifetime modelling.

Figure 3 (a) Strain-stress response for the stabilised cycle at $600^{\circ} \mathrm{C}$; (b) Cyclic softening (model and experiment) at different levels of temperatures

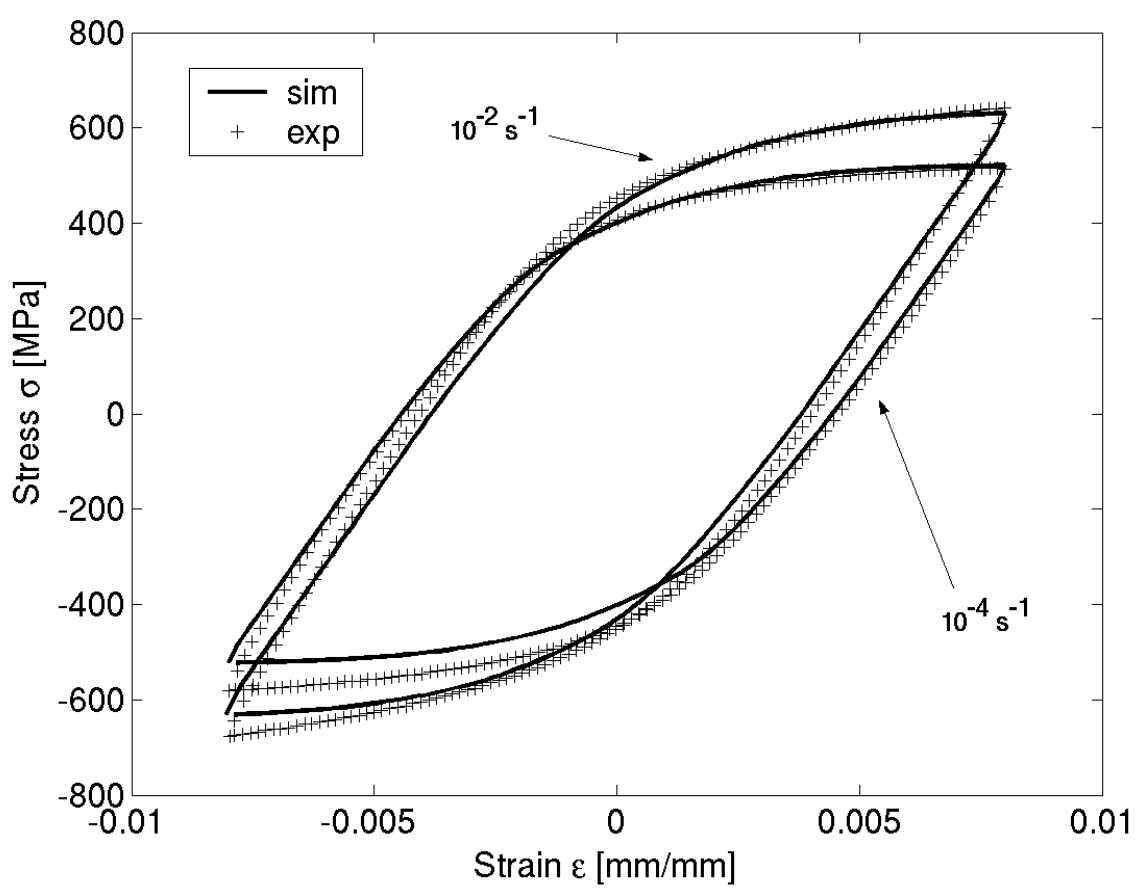

(a) 
Figure 3 (a) Strain-stress response for the stabilised cycle at $600^{\circ} \mathrm{C}$ and (b) Cyclic softening (model and experiment) at different levels of temperatures (continued)

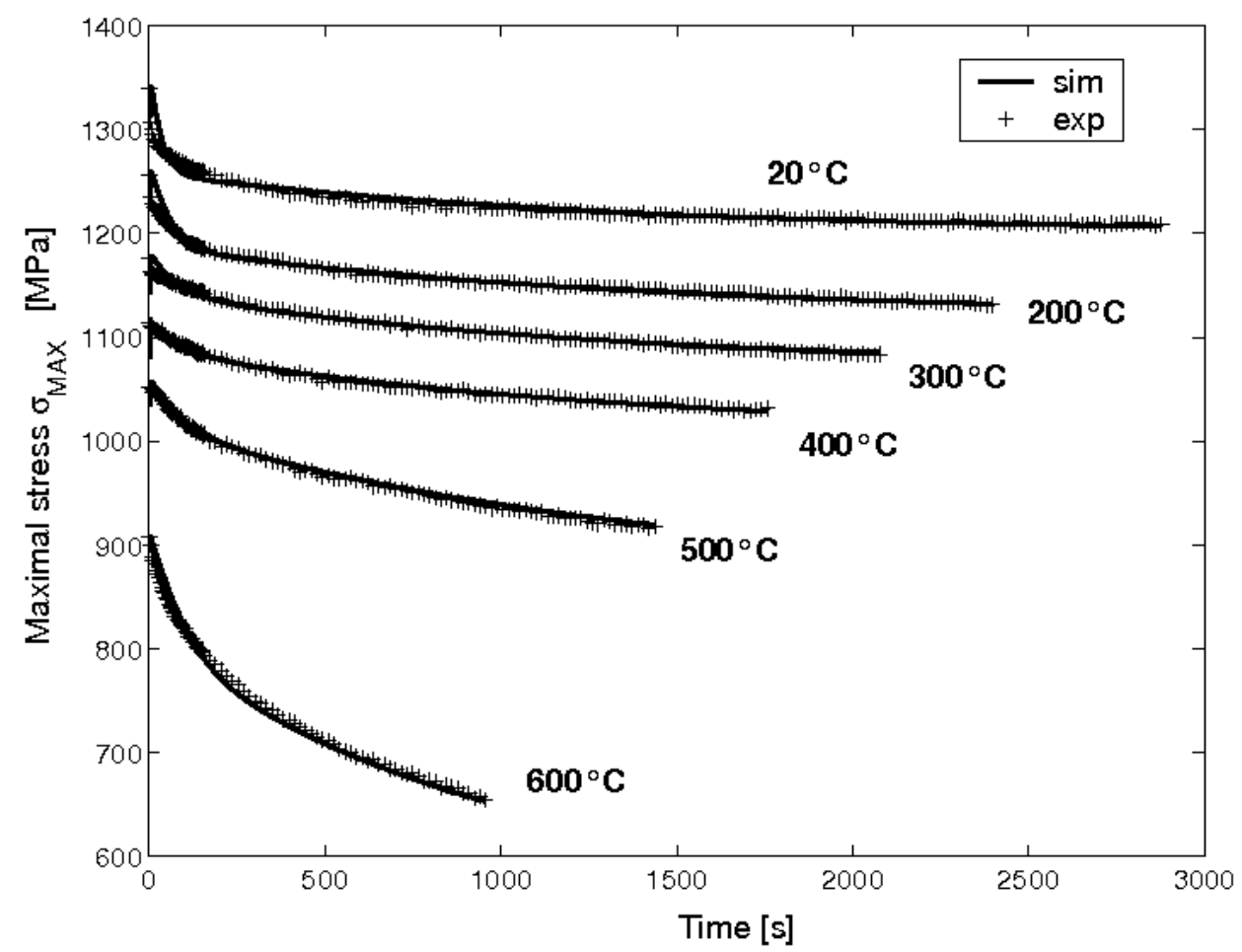

(b)

\subsection{Continuum damage model}

This model is a relevant approach to assess the number of cycles to failure and to quantify the damage evolution. It describes the evolution between the virgin state and the initiation state of the macroscopic crack. The ultimate damage stage is characterised by the fracture of the representative volume element (Lemaitre and Chaboche, 1994; Chaboche and Lesne, 1998). Thus, it can be used to investigate the damage initiation into an industrial component. It consists in a stress-formulated approach, which considers that maximal stress or stress amplitude measured or simulated at the stabilised cycle is a suitable parameter to predict lifetime. Such a framework has been investigated by many authors who have investigated ageing (Nicouleau-Bourles, 1999) or environment (Gallerneau, 1995) effects on lifetimes or have extended the model capabilities to the thermomechanical and high-cycle fatigue (Shi et al., 2000; Xiao, 2004).

Fatigue resistance is usually determined by the material lifetime assessed through the number of cycles to failure. The continuum damage approach investigated considers the stress as the critical value and can be represented by a Wöhler curve (mid-life maximal stress versus the number of cycles to failure). The lifetime fatigue tests considered in this investigation concerns the low-cycle fatigue domain of the Wöhler curve. It includes a damage variable $\mathrm{D}$ whose values can vary from 0 to 1 (rupture of the material). 
Moreover, a lot of damage investigations have shown a damage rate equal to 0 at the very beginning of the test and close to infinite near the rupture. Thus, the following formulation was adopted by many authors (Lemaître and Chaboche, 1994; Chaboche and Lesne, 1998; Velay et al., 2005):

$$
\begin{aligned}
& d D=\left(1-(1-D)^{\beta+1}\right)^{\alpha}\left(\frac{\Delta \sigma}{2 M(1-D)}\right)^{\beta} d N \\
& \alpha=1-a \frac{\left\langle\sigma_{M}-\sigma_{l}\right\rangle}{\left\langle\sigma_{u}-\sigma_{M}\right\rangle}
\end{aligned}
$$

where:

$$
\begin{aligned}
a, \beta \text { and } M & =\text { temperature- and material-dependent parameters } \\
\sigma_{M} & =\text { maximal stress } \\
\Delta \sigma & =\text { stress range } \\
\sigma_{l} & =\text { fatigue limit } \\
\sigma_{u} & =\text { ultimate stress. }
\end{aligned}
$$

Integration of the damage evolution between $\mathrm{D}=0$ (virgin material) and $\mathrm{D}=1$ (crack initiation) provides the number of cycles to failure. This expression combined with the integration of the damage evolution between $\mathrm{D}=0$ and $\mathrm{D}$ allow to formulate the damage as a function of the ratio of the number of cycles over the number of cycles to failure:

$$
\begin{aligned}
& N_{R}=\frac{1}{a(\beta+1)} \frac{\left\langle\sigma_{u}-\sigma_{M}\right\rangle}{\left\langle\sigma_{M}-\sigma_{l}\right\rangle}\left(\frac{\Delta \sigma}{2 M}\right)^{-\beta} \\
& D=1-\left(1-\left(\frac{N}{N_{R}}\right)^{\frac{1}{1-\alpha}}\right)^{\frac{1}{1+\beta}} .
\end{aligned}
$$

The fatigue tests considered in this investigation were performed at several levels of temperature. The lifetime model is able to take into account non isothermal effect using the reduced stress notion $S=\sigma / \sigma_{u}$ where $\sigma_{u}$ is the ultimate stress depending on the test temperature. Thus, the Equations (1) and (2) can be rewritten as:

$$
\begin{aligned}
& d D=\left(1-(1-D)^{\beta+1}\right)^{\alpha}\left(\frac{\Delta S / 2 M}{(1-D) / \sigma_{u}}\right)^{\beta} d N \\
& N_{R}=\frac{1}{a(1+\beta)} \frac{\left\langle 1-S_{M}\right\rangle}{\left\langle S_{M}-\sigma_{l} / \sigma_{u}\right\rangle}\left(\frac{\Delta S / 2}{M / \sigma_{u}}\right)^{-\beta} .
\end{aligned}
$$

For all the test conditions presented in this paper, only three parameters need to be identified. 


\section{Results}

\subsection{Model parameter identification}

Equation (5) and experimental fatigue tests are used to determine all the model parameters. For this purpose, Equation (5) can be represented in a bilogarithmic diagram:

$$
\log \left(\frac{\Delta S}{2}\right)=\frac{1}{\beta} \log \left(\frac{\left(M / \sigma_{u}\right)^{\beta}}{a(1+\beta)}\right)-\frac{1}{\beta} \log \left(\frac{\left\langle S_{M}-\sigma_{l} / \sigma_{u}\right\rangle}{\left\langle 1-S_{M}\right\rangle} N_{R}\right) .
$$

The slope and $\mathrm{Y}$-axis intersection (see Figure 4a) allow to identify the parameter $\beta$ and the value $\mathrm{Y}_{0}$. The number of cycles to failure can be calculated from these values:

$$
\begin{aligned}
& Y_{0}=\frac{1}{\beta} \log \left(\frac{\left(M / \sigma_{u}\right)^{\beta}}{a(1+\beta)}\right) \\
& N_{R}=\frac{\left\langle 1-S_{M}\right\rangle}{\left\langle S_{M}-\sigma_{l} / \sigma_{u}\right\rangle} e^{\beta Y_{0}}\left(\frac{\Delta S}{2}\right)^{-\beta} .
\end{aligned}
$$

Moreover, the fatigue limit ratio value $\sigma_{\mathrm{l}} / \sigma_{u}$ commonly used for the metallic materials is assumed to be 0.3 and parameter identification provides the values $\beta=12$ and $\mathrm{Y}_{0}=4 \cdot 3 \cdot 10^{-4}$. Owing to the reduced stress notion, these values are relevant whatever the temperature. Thus all the fatigue tests can be represented on a master Wöhler curve, and the results provided by the lifetime model are in a good agreement with the experiment. All of them are obtained with a scattering factor 2 on lifetimes (Figure $4 b$ ).

\subsection{Validation results}

The continuum damage model is validated in a non-isothermal case and in a multiaxial case. In the first stage, out-of-phase-compressive lifetime tests (Velay et al., 2005; Oudin, 2002) are used and the experimental numbers of cycles to failure are compared with those assessed by the lifetime model. The lifetime tests considered include temperature ranges between $200^{\circ} \mathrm{C}$ and $500^{\circ} \mathrm{C}$ or $550^{\circ} \mathrm{C}$ and different strain ranges from $1 \%$ to $1.5 \%$. The smaller and larger mechanical strain amplitudes considered are illustrated in Figure 5(a).

Several fatigue tests are investigated. Each of them can be simulated by the behaviour model (Figure 5a) and mid-life parameters can be determined. Then, results predicted by the lifetime model are obtained with a scattering factor 2 on experimental lifetimes (Figure 5b) which is usually accepted in low-cycle fatigue. In a second stage, a multiaxial validation is performed on cylindrical notched specimens. First of all, the mid-life parameters or parameters at stabilised cycle have to be calculated. Thus, the behaviour model is implemented in ABAQUS Software. 
Figure 4 (a) Reduced Wöhler curve; (b) Comparison between experimental and calculated number of cycles to failure

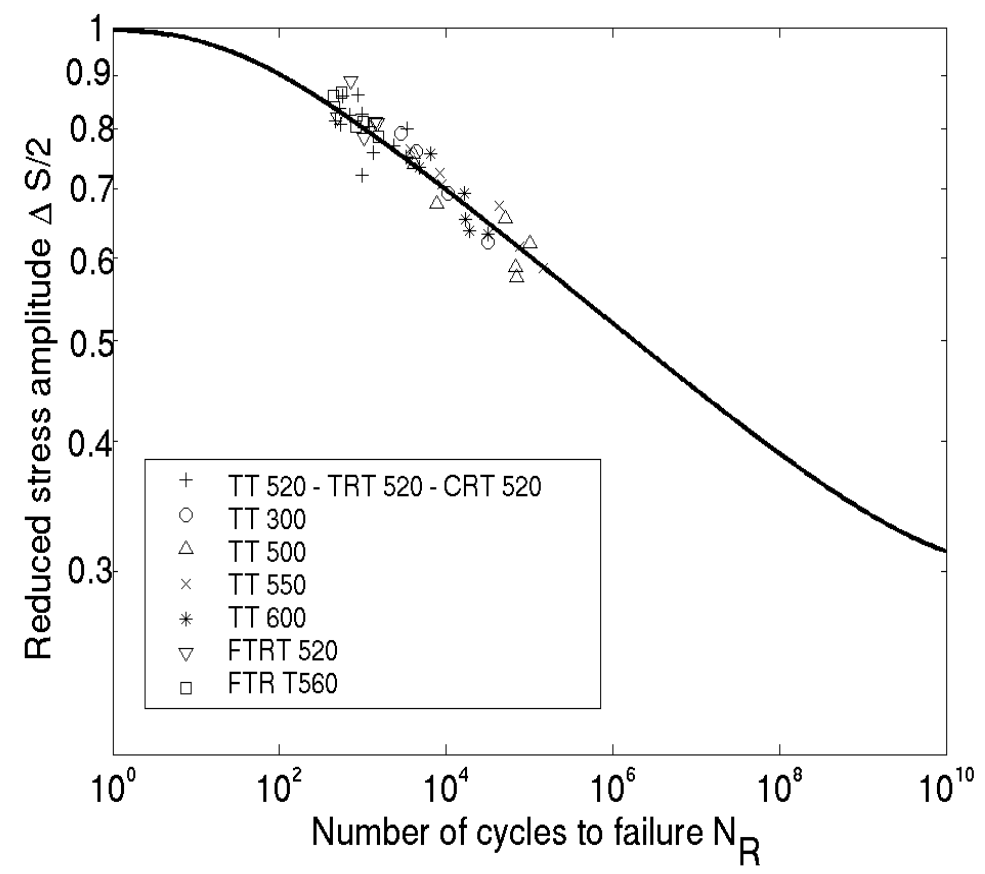

(a)

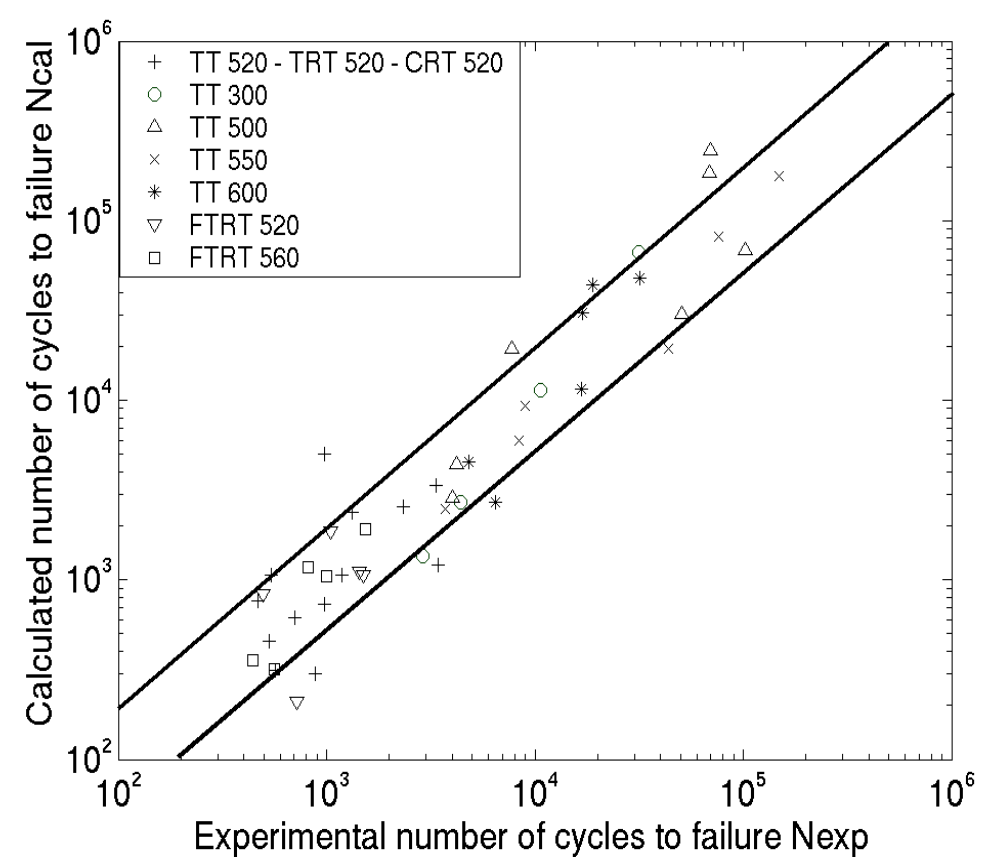

(b) 
Figure 5 (a) Mechanical strain-stress response provided by the behaviour model between $200^{\circ} \mathrm{C}$ and $550^{\circ} \mathrm{C}$; (b) Comparison between experimental and calculated number of cycles to failure for TMF tests

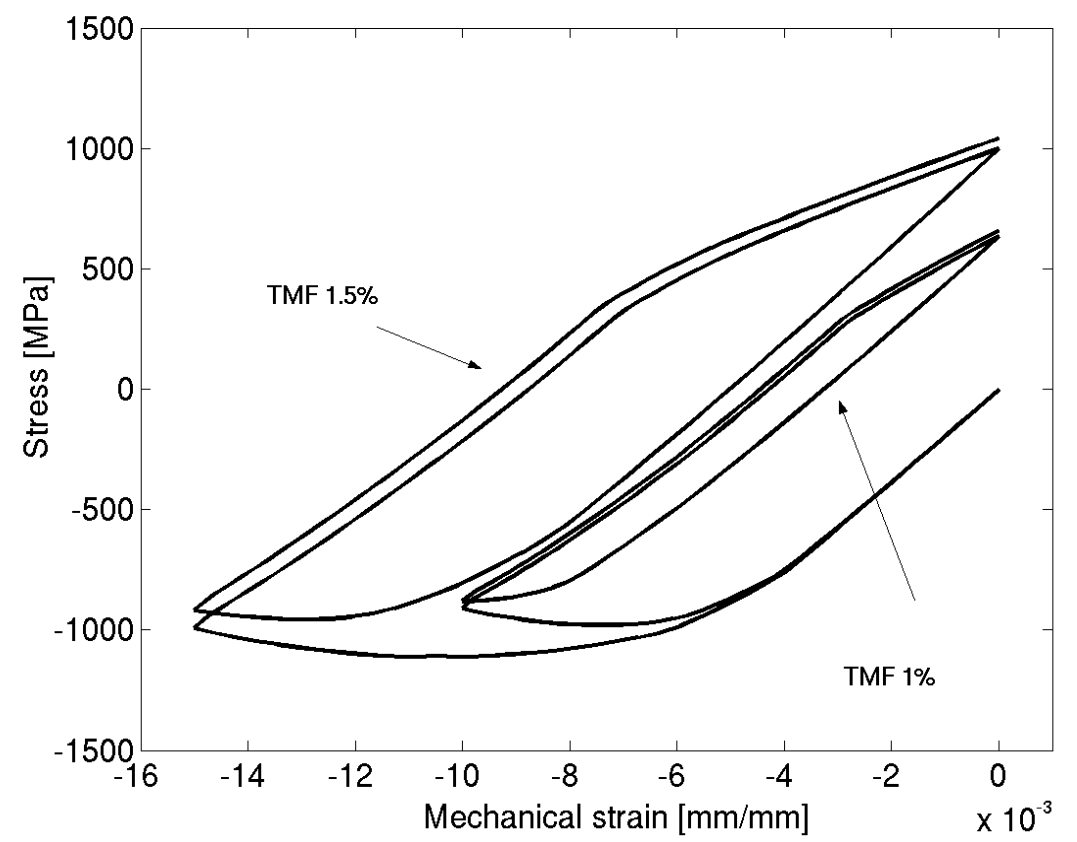

(a)

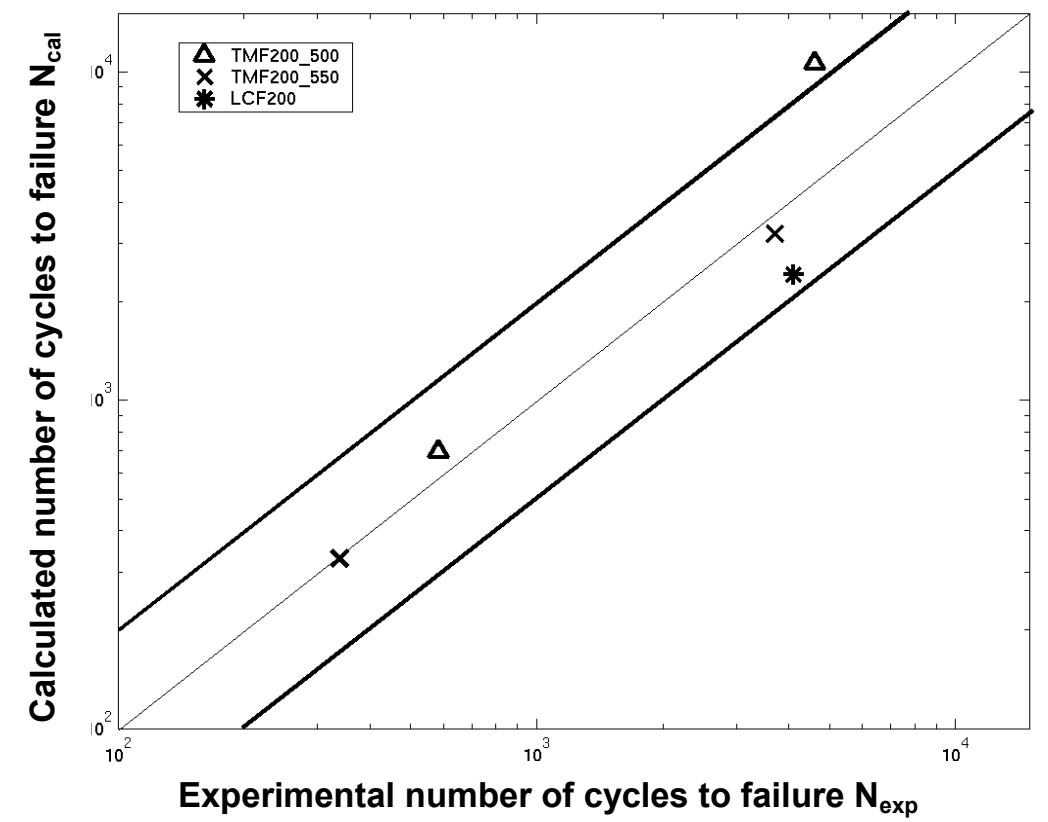

(b) 
Figure 6 (a) Axial strain-stress response within the notch (test 1); (b) axial inelastic strain-stress response within the notch (test 1 )

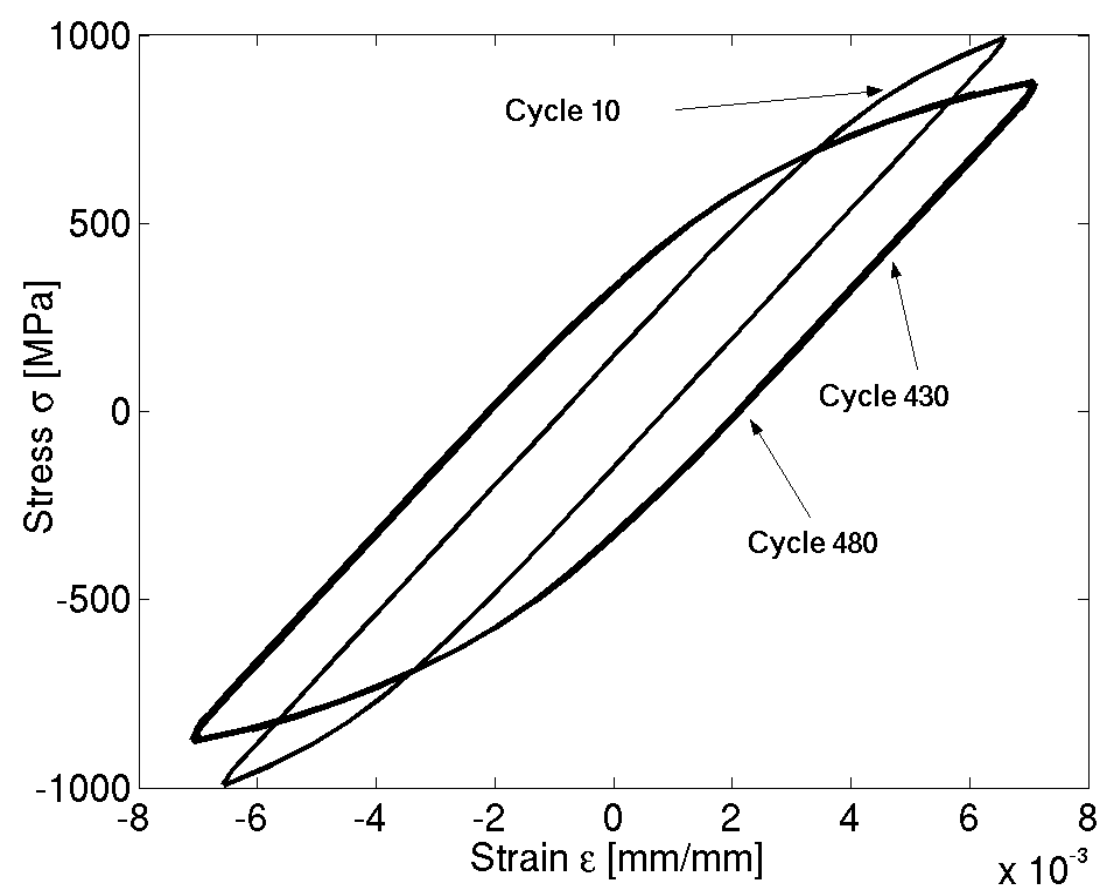

(a)

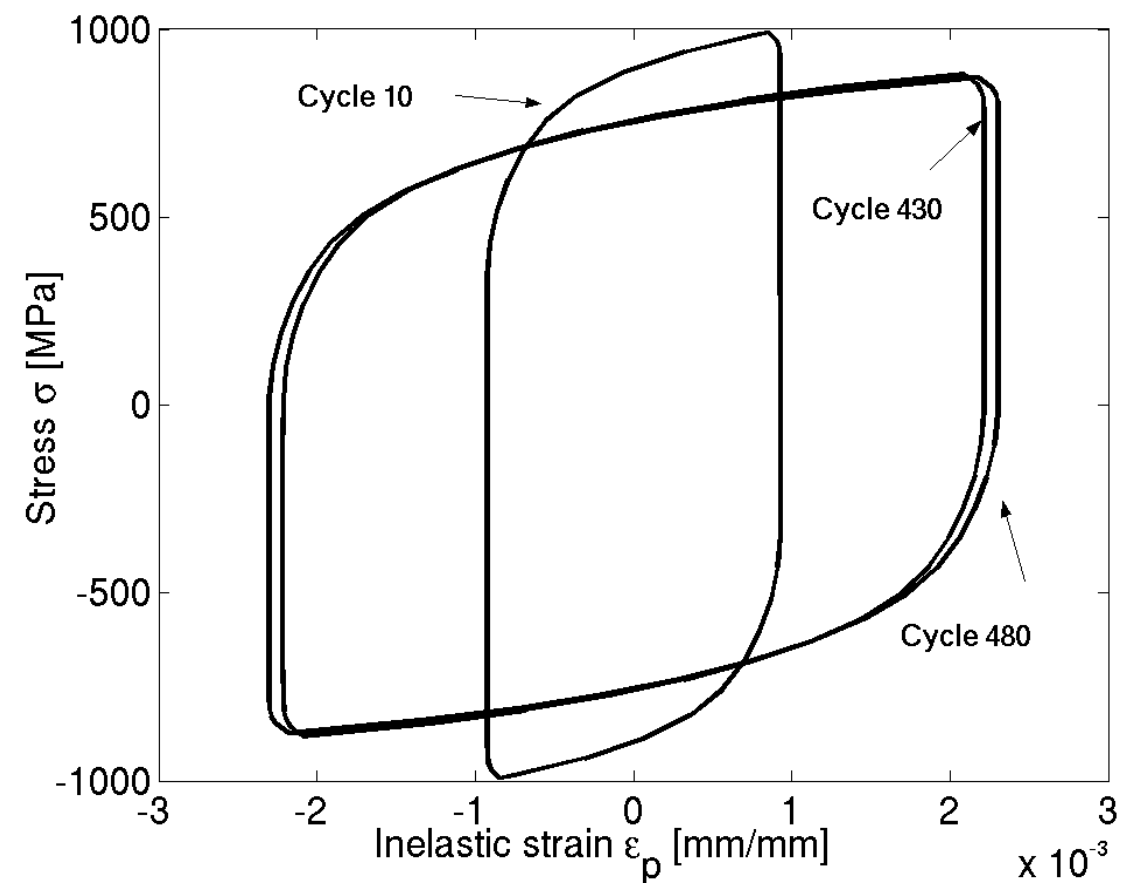

(b) 
It allows the determination of the displacement or the stress levels to apply on the specimens in order to induce a strain-stress response suitable within the notch. Then, displacement- and stress-controlled fatigue tests are simulated. Two different radii $(2 \mathrm{~mm}$ and $25 \mathrm{~mm}$ ) are considered. The loading (displacement or stress) is applied at the upper part of the specimen (above the notch). An axisymmetric finite element simulation is performed for both the specimens using ABAQUS ${ }^{\mathrm{TM}}$. In each case only half of the samples are considered and meshed. Moreover, the lifetime model formulation has to be modified in order to take into account multiaxial loadings. For that purpose, an equivalent maximal reduced stress $J\left(S_{M}\right)$ and reduced stress range $J(\Delta S)$ are introduced in the previous equations:

$$
\begin{aligned}
& J\left(S_{M}\right)=\frac{1}{\sqrt{2}} \sqrt{\left(S_{M r r}-S_{M z z}\right)^{2}+\left(S_{M r r}-S_{M \varphi \varphi}\right)^{2}+\left(S_{M z z}-S_{M \varphi \varphi}\right)^{2}+6 S_{M r z}^{2}} \\
& J(\Delta S)=\frac{1}{\sqrt{2}} \sqrt{\left(\Delta S_{r r}-\Delta S_{z z}\right)^{2}+\left(\Delta S_{r r}-\Delta S_{\varphi \varphi}\right)^{2}+\left(\Delta S_{z z}-\Delta S_{\varphi \varphi}\right)^{2}+6 \Delta S_{r z}^{2}} .
\end{aligned}
$$

Presently, three different fatigue tests were simulated for a temperature of $550^{\circ} \mathrm{C}$, a stress- and a displacement-controlled test on the sample with the small radius and a stress-controlled test on the specimen with the large radius. Displacement-controlled test will not be possible on the specimen with the large radius because of the gauge length of the extensometer being smaller than the radius of $25 \mathrm{~mm}$. Axial strain and inelastic strain-stress responses of test 1 within the notch are presented in Figure 6.

Cycles 10, 430 and 480 are reported, a cyclic softening occurs and the stabilised cycle is obtained at cycle 480 (Figure 6). The same analysis is performed in the radial and circumferential directions. Thus, the stress levels of this cycle will be considered in the lifetime model.

Table 4 presents the loading conditions and provides the number of cycles to failure predicted by the lifetime methodology. It includes one displacement-controlled test with an amplitude of $+/-0.015 \mathrm{~mm}$ conducted on a notched specimen with a small radius ( $2 \mathrm{~mm})$ and two stress-controlled tests. The first one is performed on a notched specimen with a small radius and a stress amplitude of $+/-145 \mathrm{MPa}$ and the second one on a larger radius $(25 \mathrm{~mm})$ and a more important amplitude $+/-230 \mathrm{MPa}$. For tests 2 and 3, the first cycle allows to determine the maximal stress and the stress range to be used in the lifetime model. For each simulation, the most damaged element is considered to assess the number of cycles to failure.

Table 4 Test conditions considered in the finite element simulation and number of cycles to failure predicted by the lifetime model

\begin{tabular}{lccc}
\hline Test number & Specimen radius & Loading & Number of cycles to failure assessed \\
\hline Test 1 & $2 \mathrm{~mm}$ & $+/-0.015 \mathrm{~mm}$ & 3200 \\
Test 2 & $2 \mathrm{~mm}$ & $+/-145 \mathrm{MPa}$ & 740 \\
Test 3 & $25 \mathrm{~mm}$ & $+/-230 \mathrm{MPa}$ & 200 \\
\hline
\end{tabular}




\section{Conclusion}

This paper presents a lifetime methodology based a continuum damage approach. It has been successfully applied on martensitic hot-work tool steels for uniaxial, isothermal and non-isothermal conditions. It requires a behaviour model able to reproduce thermo mechanical loadings induced in the hot-forming processes. Thus, in this investigation, capabilities of the behaviour model investigated are very interesting. Indeed, they allow a good description of the strain-stress response of the material under various test conditions. It allows to take into account a great number of loadings close to the industrial processes (different strain rates, strain amplitudes, dwell times and temperature levels). It requires a good knowledge of the material behaviour whose values have to be included in the lifetime criterion. This criterion has been successfully identified for a very large amount of fatigue tests. Indeed, provided results are suitable in low-cycle fatigue with only a scattering factor two on lifetimes. Afterwards, the mixed approach (including behaviour model and lifetime criterion) is implemented in a finite element simulation in order to validate the methodology in a multiaxial condition. For that purpose, notched specimen behaviour is simulated and the number of cycles to failure can be predicted. Some complementary simulations remain to be done. Lastly, experimental fatigue tests have to be performed and compared with results provided by the lifetime model.

\section{Acknowledgement}

The authors gratefully acknowledge F. Rossi for his contribution to the mechanical tests.

\section{Nomenclature}

$\mathrm{N}_{\mathrm{R}}$ : number of cycles to failure

$\mathrm{N}$ : current number of cycles

$\mathrm{N}_{\text {exp }}$ : experimental number of cycles to failure

$\mathrm{N}_{\text {cal }}$ : calculated number of cycles to failure

$\sigma$ : stress tensor

$\sigma_{\mathrm{u}}$ : ultimate stress

$\sigma_{1}$ : fatigue limit

$\sigma_{\mathrm{M}}$ : maximal stress obtained at the stabilised cycle (or mid-life cycle)

$\sigma_{\mathrm{m}}$ : minimal stress obtained at the stabilised cycle (or mid-life cycle)

$\Delta \mathrm{S}$ : stress amplitude

$\mathrm{S}_{\mathrm{M}}$ : maximal reduced stress obtained at the stabilised cycle (or mid-life cycle)

$\mathrm{S}_{\mathrm{m}}$ : minimal reduced stress obtained at the stabilised cycle (or mid-life cycle)

$\Delta \mathrm{S}$ : reduced stress amplitude

D: fatigue damage value

a, $\beta, M, \alpha$ : fatigue lifetime model parameters. 


\section{References}

Ahmer, Z., Velay, V., Bernhart, G. and Rezai-Aria, F. (2006) 'Cyclic behaviour of X38CrMoV5 (AISI H11) tempered martensitic hot work tool steel', Proceedings of the 7th Tooling Conference, Torino, Italy.

Cailletaud, G. and Sai, K. (1995) 'Study of plastic/viscoplasticmodels with various inelastic mechanisms', International Journal of Plasticity, Vol. 11, pp.991-1005.

Chaboche, J.L. and Lesne, P.M. (1998) 'A non-linear continuous fatigue damage model', Fatigue and Fracture of Engineering Materials and Structures, Vol. 11, pp.1-17.

Gallerneau, F. (1995) 'Etude expérimentale et modélisation de l'endommagement d'un superalliage mono cristallin revêtu pour aube de turbine', $\mathrm{PhD}$ thesis, Ecole Nationale Supérieure des Mines de Paris.

Lemaître, J. and Chaboche, J-L. (1994) Mechanics of Solid Materials, Cambridge University Press.

Nicouleau-Bourles, E. (1999) 'Etude expérimentale du vieillissement d'un alliage d'aluminium, application aux culasses automobiles', PhD thesis, Ecole Nationale Supérieure des Mines de Paris, France.

Oudin, A. (2002) 'Thermo-mechanical fatigue of hot work tool steels', PhD thesis, Ecole Nationale Supérieure des Mines de Paris, France.

Shi, H., Niu, L., Korn, C. and Pluvinage, G. (2000) 'High temperature fatigue behaviour if TZM molybdenum alloy under mechanical and thermomechanical cyclic loads', Journal of Nuclear Materials, Vol. 278, pp.328-333.

Velay, V., Bernhart, G., Delagnes, D. and Penazzi, L. (2005) 'A continuous damage model applied to high-temperature fatigue lifetime prediction of a martensitic steel', Fatigue and Fracture of Engineering Materials and Structures, Vol. 28, pp.1009-1023.

Velay, V., Bernhart, G. and Penazzi, L. (2006) 'Cyclic behavior modelling of a tempered martensitic hot work tool steel', International Journal of Plasticity, Vol. 22, pp.459-496.

Xiao, Y. (2004) 'A multi-mechanism damage coupling model', International Journal of Plasticity, Vol. 26, pp.1241-1250. 